\title{
Control of Rhizopus: Induced decay in watermelon (Citrullus lanatus L.) fruits using heat treatment
}

\author{
Oluwole Olakunle Oladele
}

Department of Biology. Federal University of Technology. Akure. Ondo State. Nigeria. Email: prophetoladele2014@gmail.com.

\begin{abstract}
Control of Rhizopus, induced decay in watermelon (Citrullus lanatus) fruits using heat treatment was investigated. Watermelon fruits of uniform size and colour were selected, washed with clean water and disinfected after harvest. The fruits were then inoculated with spore suspension containing $3.02 \times 10^{3}$ spores $\mathrm{mL}^{-1}$ of Rhizopus sp. inoculated fruits were immersed separately in a water bath at $50{ }^{\circ} \mathrm{C}$ for 2,3 and $5 \mathrm{~min}$ and $53{ }^{\circ} \mathrm{C}$ for 2 and $3 \mathrm{~min}$. Control fruits were inoculated but not heat treated. Each set up was in 3 replicates. Control and treated fruits were then stored in cleaned transparent plastic containers at $28{ }^{\circ} \mathrm{C} \pm 2{ }^{\circ} \mathrm{C}$ and $75 \%-80 \%$ relative humidity and observed daily for disease severity. Result obtained on day 5 of storage showed there was no significance difference $(p \geq 0.05)$ in the disease severities of control and all the treated fruits. The disease severity of both the control and all treated fruits was $1.00 \pm 0.28$ which implied that the fruits were healthy (disease free). However as storage period progressed to day 25, only fruits treated at $53{ }^{\circ} \mathrm{C}$ for $3 \mathrm{~min}$ maintained disease severity of $1.00 \pm 0.00$, which implied that the fruits were still disease free, recording mean appearance and taste index of 3.50 and 2.00, respectively, which thus indicated good appearance and sweet taste of the fruits. Other treatments recorded various degrees of rottenness. Hence, treatment at $53^{\circ} \mathrm{C}$ for $3 \mathrm{~min}$ could be considered as the most effective for extending the shelf life of water melon fruits among all temperatures and time combinations experimented in the study.
\end{abstract}

Keywords: Disease severity; Hot water; Time; Pathogen; Spore suspension; Storage.

\section{Introduction}

Watermelon (Citrullus lanatus) fruits belong to cucurbitaceae family, which consists of nearly 100 genera and over 750 species. In Nigeria, the largest production of watermelon fruits comes from the northern part of the country, where the suitable agro- ecology is found. They are widely distributed in the tropics and subtropics, and a few species occur in temperate region. Economically, Watermelon is an important fruit crop and valuable alternative source of water in desert areas (Perkins-Veazie and Yamaguchi, 2001). It is a good source of lycopene, citrulline and important minerals and vitamins. It has the highest lycopene content among fresh fruits and vegetables (Lurie, 1998). Watermelon contains $60 \%$ more lycopene than tomato. Lycopene in the human diet is 
associated with prevention of heart attacks and certain cancers. Rind of watermelon contains an important natural compound called citrulline, an amino acid that the human body makes from food.

However, watermelon fruits are mostly threatened by some pathogenic fungi which are seed-borne and also soilborne such as Mucor spp and Rhizopus spp. Various post-harvest control measures of fruits are: use of low temperature, heat treatment, use of fungicides etc. Post-harvest disease of water melon fruits are primarily controlled by application of conventional fungicides. However, the development of resistance by pathogens to fungicides (Holmes and Eckert 1999) and the increased demand for fruit free of hazardous chemicals have revived interest in heat treatment (Smilanick et al., 2003). Heat is usually applied to a fruit commodity via air or water (BarkaiGolan and Philips 1991). Nevertheless, water is more efficient than air by virtue of its higher heat transfer coefficient (Jacobi and Giles, 1997).

The use of heat treatment is therefore investigated in this research work as alternative non chemical control measure against Rhizopus $\mathrm{sp}$ on watermelon fruits.

\section{Materials and methods}

\section{Source of fruits and medium preparation}

Mature, green healthy

watermelon fruits were harvested from Ipinsa $\left(7^{\circ} 13^{\prime} 26^{\prime \prime} \mathrm{N}\right.$ and $\left.5^{\circ} 39^{\prime} 0^{\prime \prime} \mathrm{E}\right)$ village located along Oke-Odu, in Akure, Ondo State, Nigeria, and brought to the research laboratory of Biology Department, FUTA. Fruits of uniform size and colour were selected and washed with clean water and immersed in $10 \%$ sodium hypochlorite solution for $5 \mathrm{~min}$ and allowed to air dry. Medium was prepared by dispensing $5.0 \mathrm{~g}$ of Potato Dextrose Agar into a sterile $250 \mathrm{~mL}$ conical flask. $100 \mathrm{~mL}$ of distilled water was added to the agar and agitated carefully for homogeneity of the medium. The flask was corked and placed in the autoclave where it was sterilized for 15 $\min$ at $121{ }^{\circ} \mathrm{C}$. Tetracycline was added to the sterilized medium and the medium after being allowed to cool was poured into sterile Petri dishes and left to solidify.

\section{Isolation from infected watermelon fruits}

Isolation of associated fungi from spoilt watermelon fruit was made by cutting out the interface between the healthy and the disease tissue and placing pieces of the affected fruit and without surface sterilization on plates of solidified Potato Dextrose Agar (PDA). The plates were then incubated at for 3 days. Subcultures of the isolate were prepared by transferring agar cut with distinct mycelium to sterilized Petri dishes containing solidified PDA and then incubated at $28{ }^{\circ} \mathrm{C} \pm 2{ }^{\circ} \mathrm{C}$ until pure cultures were obtained. The resulting pure culture was then used for morphological characterizations of the isolate.

After incubation, identification of the isolate was based mainly on the structural feactures as seen in the culture plate as well as microscopic characteristics. A drop of cotton in blue lactophenol solution was put on a slide. The isolate was placed on a slide. This was covered with a cover slip, excess liquid was drained with filter paper and the isolate was examined under microscope. Examination was done with $\mathrm{x} 40$ objective for the presence and type of hyphae, mycelium whether clear or dark and spore morphology. The isolate was then identified using the text of Alexopoulous et al. (1996).

Preparation of spore
suspension and treatment of
inoculated watermelon fruits with
hot water

Sterile water was poured into a conical flask containing the pure culture 
and shaken vigorously to dislodge the spores from the vegetative hyphae. The wash water was collected in a sterilized beaker. After serial dilution to $\times 10^{3}$, one milliliter of the suspension was injected using sterile syringe and needle into watermelon fruits and allowed to stay for $12 \mathrm{~h}$ before heat treatment. The suspension used to inoculate the watermelon fruits before treatment contained $3.02 \times 10^{3}$ spores $/ \mathrm{mL}$ of the isolate. Inoculated watermelon fruits were immersed separately in a water bath at $50{ }^{\circ} \mathrm{C}$ for 2,3 and 5 minutes, $53^{\circ} \mathrm{C}$ for 2 and $3 \mathrm{~min}$. Each set up was in three replicates. Control fruits were inoculated but not heat treated. All fruits were placed in cleaned transparent plastic containers and stored in $75 \%-80 \%$ relative humidity at $28{ }^{\circ} \mathrm{C} \pm 2{ }^{\circ} \mathrm{C}$ and observed daily for disease severity.

Both the control and all heat treated watermelon fruits stored in clean plastics containers at $75 \%-80 \%$ relative humidity at $28^{\circ} \mathrm{C} \pm 2{ }^{\circ} \mathrm{C}$ were assessed daily for disease severity using the modified scale of Arekemase and Oyeyiola (2007) where: 1 = disease free; 2 = slight decay up to $10 \%$ of the fruit surface; $3=$ moderate decay up to $35 \%$ of the fruit surface; $4=$ severe decay $\geq 45 \%$ of the fruit surface. Decay was recognized by dark coloration on the fruit or by appearance of whitish mycelium on the fruit surface. Sensory evaluation of fruits which remained healthy after 30 days of storage was done by an informal panel of 10 judges. Fruit appearance was observed. Fruit samples from each treatment were labelled and laid out for the panel of judges to avoid biased judgment. Appearance index was determined by scoring graded fruit as very good/no sign of wilting on the entire fruit surface (4); good/no sign of wilting up to $90 \%$ of the fruit surface (3); showing sign of wilting up to $45 \%$ of the fruit surface (2) or wilted (1) (Babarinsa and Williams, 2002). Wittiness was evident by dark/brown colouration or appearance of mycelium on the fruit surface. Taste index was determined on hedonic scale of 5 ; where 1 = very sweet; $2=$ sweet; $3=$ not sweet; $4=$ no taste and 5 = inedible (Lamond, 1997).

\section{Statistical Analysis}

The data obtained for disease severity were subjected to analysis of variance and where significant, the means were compared at $5 \%$ level of probability using New Duncan's Multiple Range Test (SPSS Version 20).

\section{Results}

\section{Effect of hot water treatment on Rhizopus- induced decay of water melon fruits during storage}

Result obtained on day 5 of storage showed there was no significance difference $(p \geq 0.05)$ in the disease severities of control and all the treated fruits. The disease severity of both the control and all treated fruits was $1.00 \pm 0.28$ (Figure 1). However, on day 10 of storage, there was a significant difference $(p \leq 0.05)$ in the disease severity of control when compared with other treated fruits. The disease severity of fruits treated at $50{ }^{\circ} \mathrm{C}$ for 2,3 and 5 min were $1.67 \pm 0.14,1.33$ \pm 0.05 and $1.00 \pm 0.56$, respectively (Figure 2). 


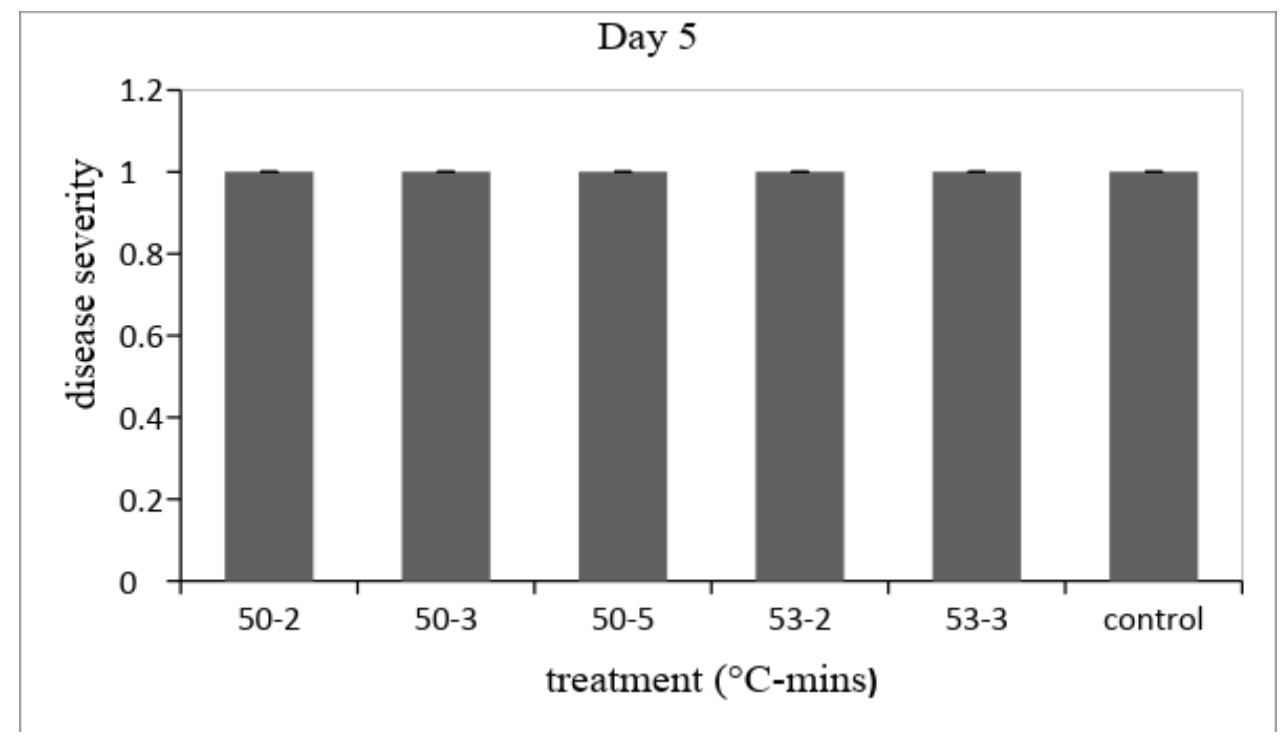

Figure 1. Effect of hot water treatment on disease severity of Watermelon fruits after 5 days of storage.

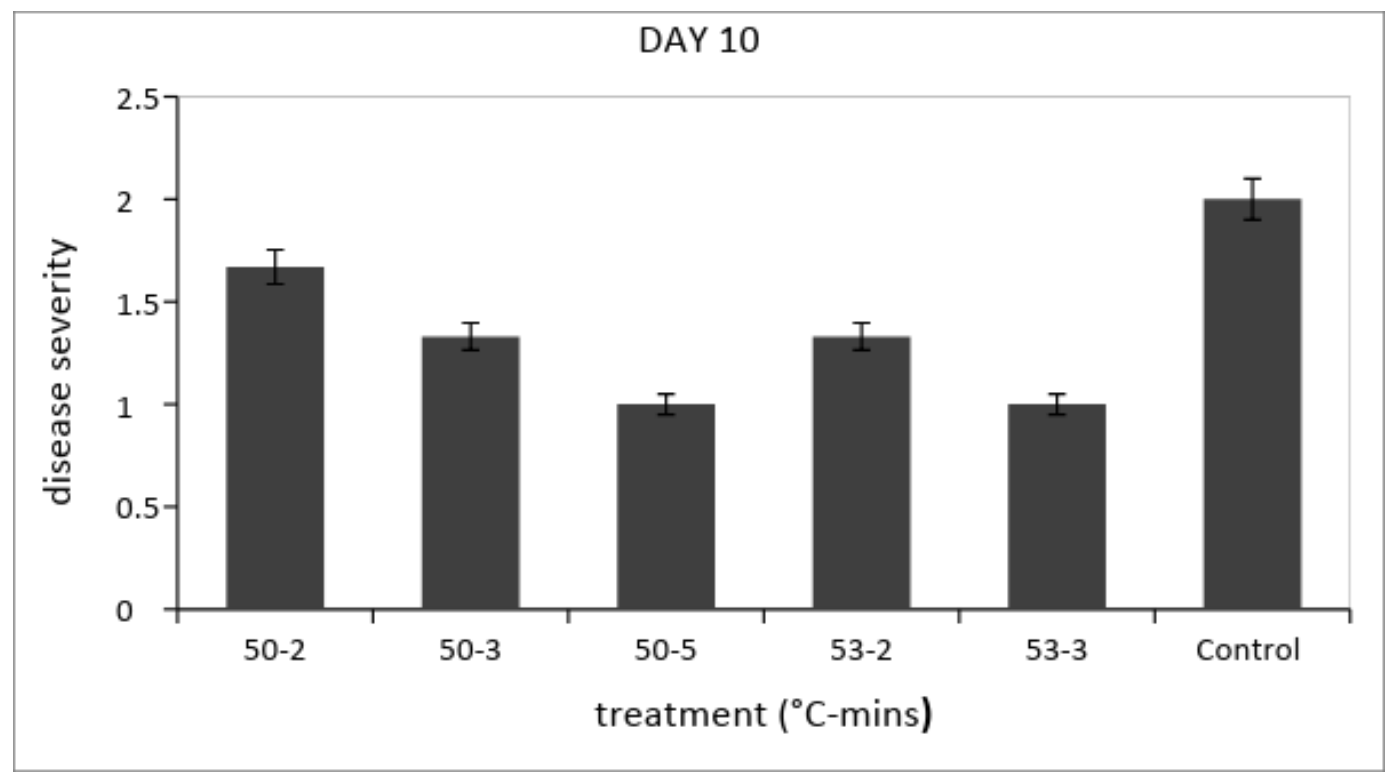

Figure 2. Effect of hot water treatment on disease severity of Watermelon fruits after 10 days of storage.

For treatment at $53^{\circ} \mathrm{C}$ for 2 and 3 min, the disease severities were $1.33 \pm$ 0.14 and $1.00 \pm 0.57$ (Figure 2) while the disease severity of control was $2.00 \pm$ 0.79 (Figure 2). On day 15 of storage, there was a significant difference $(p \leq 0.05)$ in the disease severity of control when compared with other treated fruits. The disease severity of fruits treated at $50^{\circ} \mathrm{C}$ for 2,3 and $5 \mathrm{~min}$ were $2.33 \pm 0.34,2.33 \pm 0.05$ and $1.00 \pm$ 0.56, respectively (Figure 3 ). For treatment at $53{ }^{\circ} \mathrm{C}$ for 2 and $3 \mathrm{~min}$, the disease severities were $1.33 \pm 0.14$ and $1.00 \pm 0.57$ (Figure 3) while the disease severity of control was $3.00 \pm 0.79$ (Figure 3). 


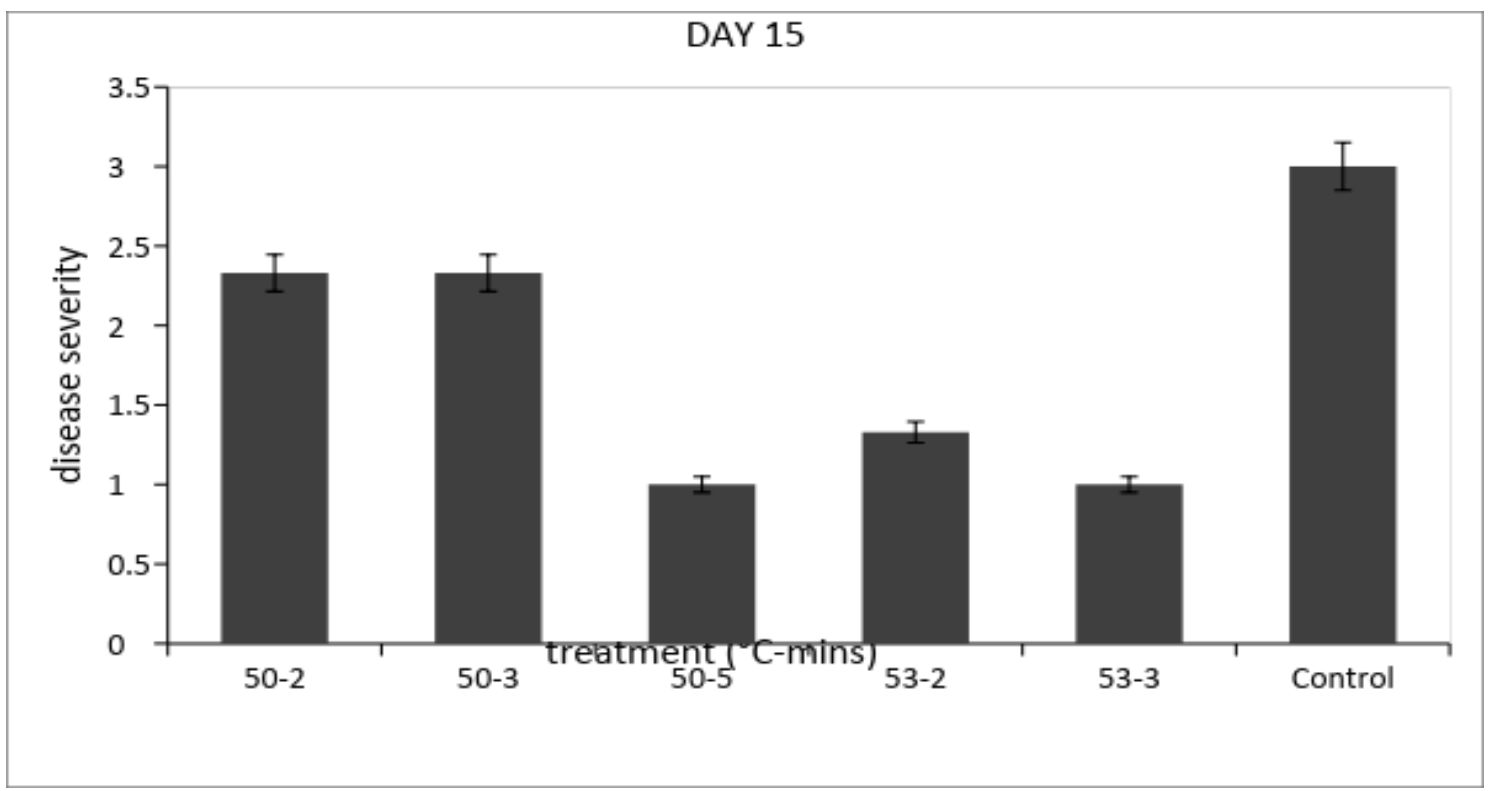

Figure 3. Effect of hot water treatment on disease severity of Watermelon fruits after 15 days of storage.

On day 20 of storage, there was a significant difference $(p \leq 0.05)$ in the disease severity of control when compared with other treated fruits. The disease severity of fruits treated at $50{ }^{\circ} \mathrm{C}$ for 2,3 and $5 \mathrm{~min}$ were $3.67 \pm 0.34,3.67$ \pm 0.05 and $2.00 \pm 0.56$, respectively (Figure 4). For treatment at $53{ }^{\circ} \mathrm{C}$ for 2 and $3 \mathrm{~min}$, the disease severities were $1.33 \pm 0.64$ and $1.00 \pm 0.97$ (Figure 4) while the disease severity of control was $4.00 \pm 0.39$ (Figure 4). On day 25 of storage, there was also a significant difference $(p \leq 0.05)$ in the disease severity of control when compared with other treated fruits.

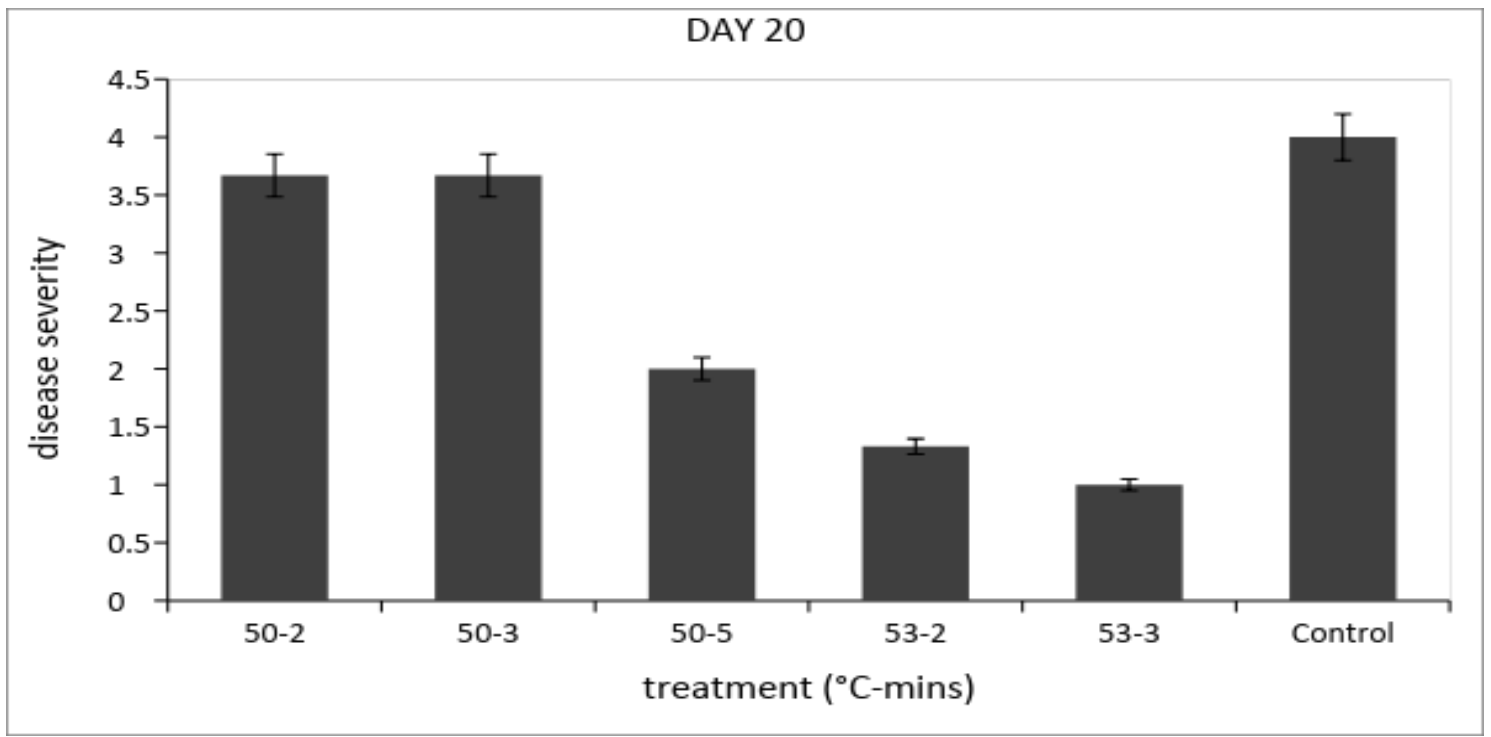

Figure 4. Effect of hot water treatment on disease severity of Watermelon fruits after 20 days of storage. 
The disease severity of fruits treated at $50{ }^{\circ} \mathrm{C}$ for 2,3 and $5 \mathrm{~min}$ were $4.00 \pm 0.44,4.00 \pm 0.15$ and $3.00 \pm 0.76$, respectively (Figure 5). For treatment at $53^{\circ} \mathrm{C}$ for 2 and $3 \mathrm{~min}$, the disease severities were $3.33 \pm 0.24$ and $1.00 \pm$ 0.00 (Figure 5) while the disease severity of control was $4.00 \pm 0.69$ (Figure 5). Hot watermelon treatment at $53{ }^{\circ} \mathrm{C}$ for $3 \mathrm{~min}$ was judged the best among all the treatments investigated. By day 25 in storage, the mean appearance and taste of the treated fruits were 3.50 and 2.00, respectively (Table 1), indicating good appearance and sweet taste of the treated fruits.

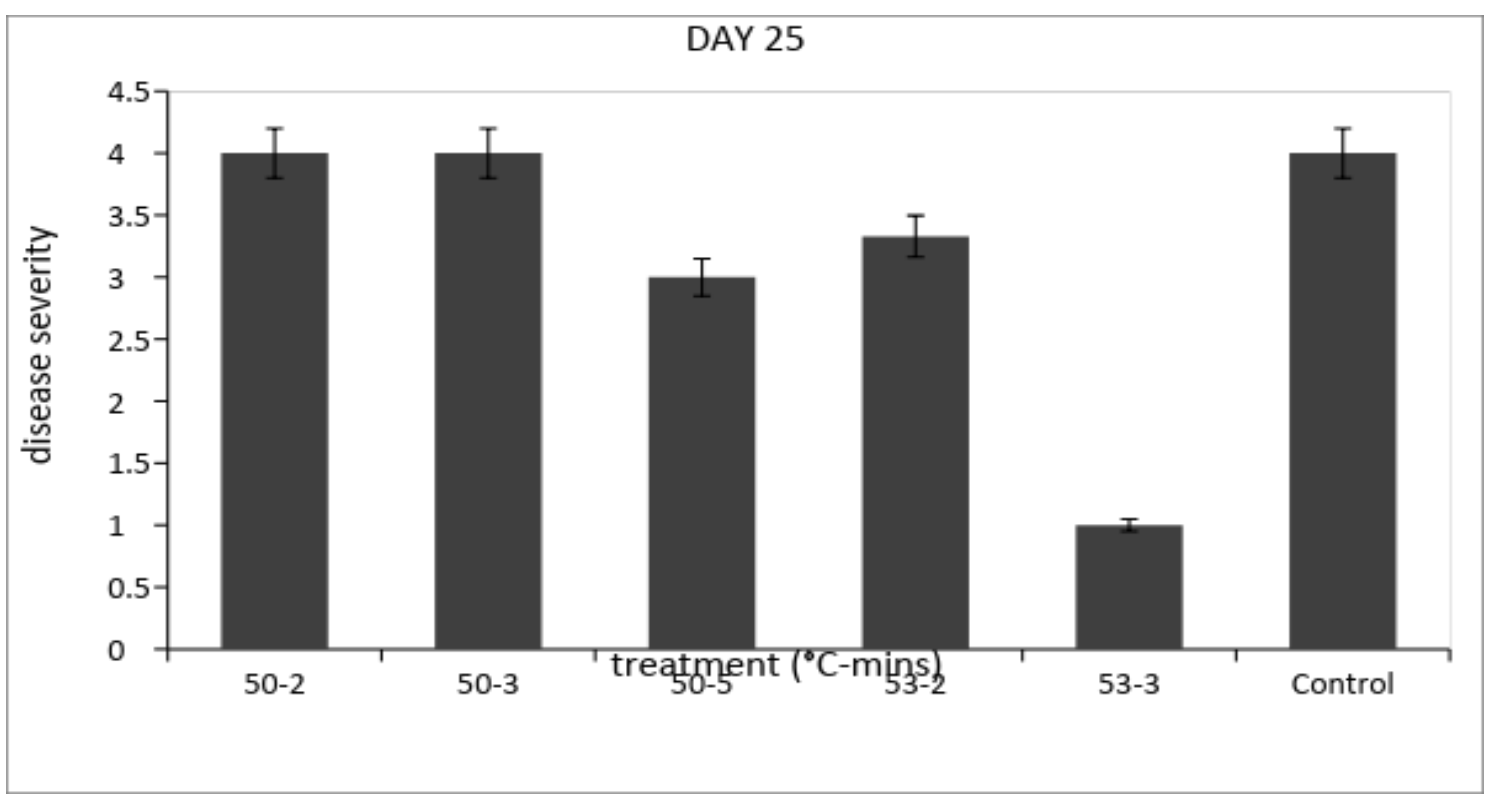

Figure 5. Effect of hot water treatment on disease severity of Watermelon fruits after 25 days of storage.

Table 1. Sensory attributes of the infected watermelon fruits on day 25 of storage after hot water treatment at $53{ }^{\circ} \mathrm{C}-3 \min$ (most effective treatment).

\begin{tabular}{|l|c|c|}
\hline Sensory attributes & Sensory values & Remarks \\
\hline Fruit appearance & $3.50 \pm 0.20$ & Good appearance \\
\hline Fruit taste & $2.00 \pm 0.00$ & Sweet taste \\
\hline
\end{tabular}

Each value is a mean of ten replicates.

\section{Discussion}

Results obtained on day 25 of storage showed that only fruits treated at $53{ }^{\circ} \mathrm{C}$ for $3 \mathrm{~min}$ were disease free. Other treatment temperatures and times recorded various degrees of rottenness. Hence, treatment at $53{ }^{\circ} \mathrm{C}$ for 3 min can be considered as the most effective treatment among all the treating temperature-time combinations. The efficacy of this effective treatment cannot but be connected with the physiological condition of the fruit which clearly influences the susceptibility of the fruit to decay. More so, part of the efficacy of hot water is due to its potential to remove spores from the wounds and also the direct effect of heat on the pathogenic agent. 
This was also the similar observation of Lurie (1998) who reported that immersing orange fruits in hot water for 3 minutes at $53{ }^{\circ} \mathrm{C}$ significantly controlled Penicillium digitatum. Also, Llus et al. (2001) reported that hot water controlled blue mould in oranges at $50{ }^{\circ} \mathrm{C}$ to $55^{\circ} \mathrm{C}$ for 3 min each for 14 days of storage.

Similarly, observation from this study showed that treatment at $53{ }^{\circ} \mathrm{C}$ for 3 min successfully controlled Rhizopus $\mathrm{sp}$ for 25 days of storage, although efficacy of hot water treatment depends on the product and is restricted to a narrow range of temperatures and exposure time. Moreover, variety of crop and pre harvest agronomic practices in the field and climatctic regions of crops grown could vary with hot water efficiently (De Costa and Erabadupitiya, 2005).

Lurie (1998) reported that heat treatment has a beneficial method for control of postharvest problems especially diseases on various horticultural produce. Heat treatments of fruit have been demonstrated to protect against postharvest decay. Heat treatments have been reported to inhibit postharvest fungal germination and growth (Fallik et al., 2003). The benefits of pre storage heat treatment on various horticultural produce especially in controlling pathological problems have been reported (Aborisade and 0jo, 2002; Aborisade and Akomolafe, 2007). Therefore, Use of heat treatment for postharvest control of pathogen on fruits due to ease of preparation, application and being free of risks due to fungicide residues is special importance and regarding the efficacy of $53{ }^{\circ} \mathrm{C}-3 \mathrm{~min}$ for effective decay control as demonstrated in this study, use of $53{ }^{\circ} \mathrm{C}-3 \mathrm{~min}$ is hereby recommended for control of pathogens on water melon fruits.

\section{Conclusion}

The results of this research work revealed that all the selected hot water (HW) treatments at $50{ }^{\circ} \mathrm{C}-2 \mathrm{~min}, 50{ }^{\circ} \mathrm{C}-3$ min, $\quad 50{ }^{\circ} \mathrm{C}-5 \mathrm{~min}, \quad 53^{\circ} \mathrm{C}-2 \mathrm{~min}$ and $53^{\circ} \mathrm{C}-3 \mathrm{~min}$ delayed the growth of Rhizopus sp for the first 5 days of storage. Interestingly, treatment at $53{ }^{\circ} \mathrm{C}-3 \mathrm{~min}$ showed $100 \%$ effectiveness for the control of Rhizopus sp on watermelon by 25 th day of storage.

\section{Conflicts of interest}

The author declares that have no conflict of interests.

\section{References}

Aborisade, A. T.; Akomolafe, O. M. Effect of heat treament of plaintain (Musa paradisiaca) from peel characteristics and control of decay by Fusarium verticilliodes. Asian Journal of Plant Science, v. 6, p. 523-527, 2007.

Aborisade, A. T.; Ojo, F. H. Effect of postharvest hot air treatment of tomatoes (Lycopersicun esculentum) on storage life and decay caused by Rhizopus stolonifer. Journal of Plant Disease and Protection, v. 109, p. 639-645, 2002.

Arekemase, M. O.; Oyeyiola, G. P. Fungi associated with spoiled citrus fruits obtained from llorin. Centre Point (Science Edition), v. 4, p. 138-149, 2007.

Alexopoulous, C. J.; Mims, C. W.; Blackwell, M. Introductory Mycology. New York: John Wiley and Sons, 1996.

Babarinsa, F. A.; Williams, J. O. Control of weight loss in Valencia oranges using Waxed Paper Wrappers. Postharvest Science, v. 1, p. 78-80, 2002.

Barkai-Golan, R.; Phillips, D. J. Postharvest heat treatments of fresh fruits and vegetables for decay control. Journal of Plant Disease, v. 75 , p. 10851089, 1991.

De Costa, D. M.; Erabadupitya, H. R. An integrated method to control postharvest diseases of banana using a member of the Burkhoderia cepacia Complex. Postharvest Biology Technology, v. 36, p. 31-39, 2005. 
Fallik, E.; Klein, J.; Grinberg, S.; Gambourg, M.; Klein, J. D.; Lurie, S. Prestorage heat treatment reduces pathogenicity of Penicillium expansum in apple fruit. Journal of Plant Pathology, v. 45, p. 92-97, 2003.

Holmes ,G. L.; Eckert, J. W. Sensitivity of Penicillium digitatum and P. italicum to post harvest citrus fungides in California. Phytopathology, v. 89, p. 716-721, 1999. Jacobi, K. K.; Giles, J. E. Quality of 'Kesington' mango (Mangifera indica Linn.) fruit following combined vapour heat disinfestations and hot water disease control treatments. Postharvest Biology Technology, v. 12, p. 285-292, 1997.

Lamond, E. Laboratory method of sensory evaluation of foods. Canada: Canada Central Experimental Station, 1997.
Lluis, P.; Joseph, L. S.; Joseph, U.; Immaculada, V. Control of post-harvest blue and green molds of oranges by hot water, sodium carbonate, and sodium bicarbonate. Journal of Plant Disease, $\mathrm{v}$. 85, p. 371-376, 2001.

Lurie, S. Post harvest heat treatment review. Postharvest Biology Technology, v. 14, p. 257-269, 1998.

Perkins-Veazie, A. U.; Yamaguchi, E. P. World vegetables: Principles, production and nutritive value. 2. ed. New Yoork: Chapman and Hall, 2001.

Smilanick, J. L.; Sorenson, D.; Mansoir, M.; Aieyabei, J.; Plaza, P. Impact of a brief post-harvest hot water drench treatment on decay, fruit appearance and microbial populations of lemons and oranges. Horticulural Technology, v. 13, p. 333338, 2003. 